Portland State University

PDXScholar

$11-29-1988$

\title{
Coverbal Behavior of Aphasic and Right Hemisphere Damaged Subjects in Conversation
}

Jill Duvall

Portland State University

Follow this and additional works at: https://pdxscholar.library.pdx.edu/open_access_etds

Part of the Speech and Hearing Science Commons

Let us know how access to this document benefits you.

\section{Recommended Citation}

Duvall, Jill, "Coverbal Behavior of Aphasic and Right Hemisphere Damaged Subjects in Conversation" (1988). Dissertations and Theses. Paper 3846.

https://doi.org/10.15760/etd.5718

This Thesis is brought to you for free and open access. It has been accepted for inclusion in Dissertations and Theses by an authorized administrator of PDXScholar. Please contact us if we can make this document more accessible: pdxscholar@pdx.edu. 
AN ABSTRACT OF THE THESIS OF Jill Duvall for the Master of Arts in Speech Communication: Emphasis in

Speech and Hearing Science presented November 29, 1988.

Title: Coverbal Behavior of Aphasic and Right Hemisphere Damaged Subjects in Conversation

APPROVED BY MEMBERS OF THE THESIS COMMITTEE:

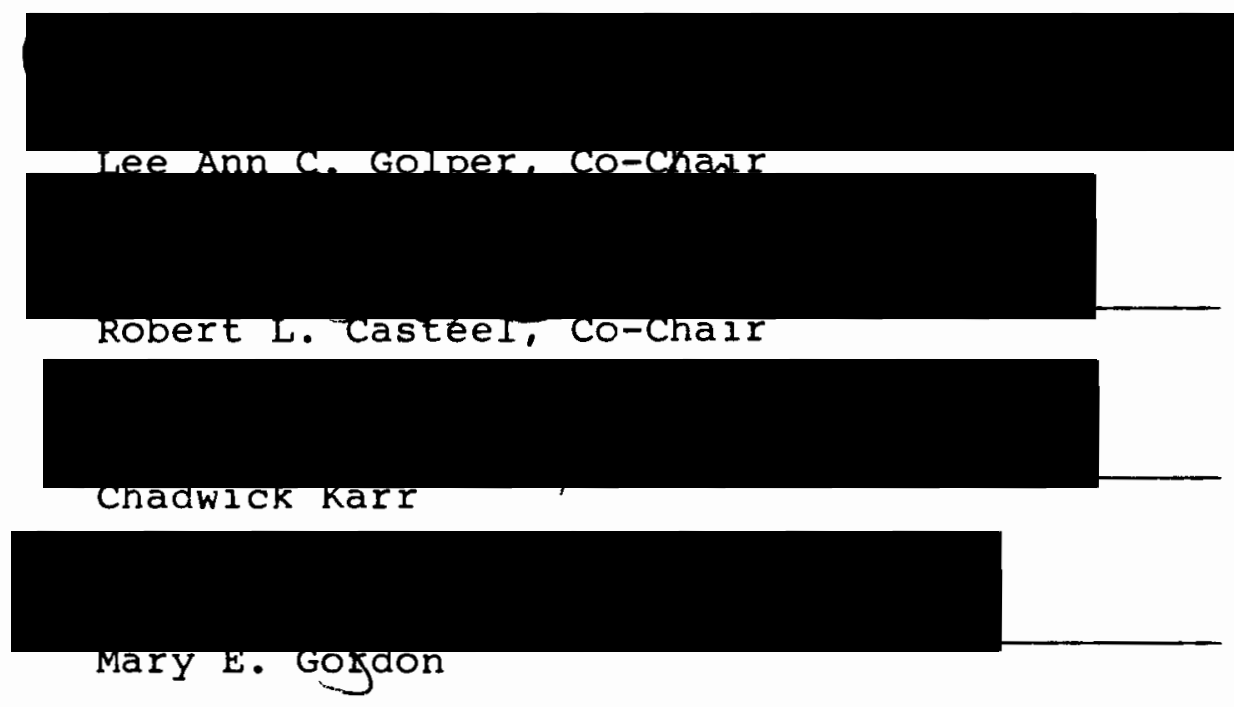

The frequency and duration of six coverbal behaviors were examined in two experimental groups and one control group. Conversational samples of ten aphasic subjects, ten right hemisphere damaged (RHD) subjects, and ten matched, non-brain damaged (NBD) control subjects were scored for frequency and duration of eye contact, head nod, head shake, 
head tilt, smile and eyebrow raise. Only the frequency of smile was found to differ significantly; the RHD subjects smiled less often than either of the other two groups. 


\title{
COVERBAL BEHAVIOR OF APHASIC AND \\ RIGHT HEMISPHERE DAMAGED \\ SUBJECTS IN CONVERSATION
}

by

JILL DUVALL

A thesis submitted in partial fulfillment of the requirements for the degree of

\author{
MASTER OF ARTS \\ in \\ SPEECH COMMUNICATION \\ with emphasis in \\ SPEECH AND HEARING SCIENCE
}

Portland State University 
TO THE OFFICE OF GRADUATE STUDIES:

The members of the Committee approve the thesis of Jill Duvall presented November 29, 1988.

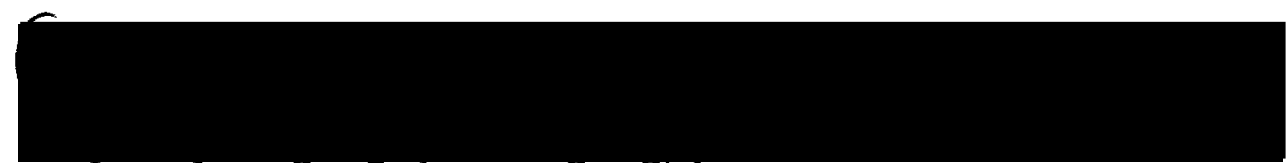

Lee Ann C. Golper, Co-Chair

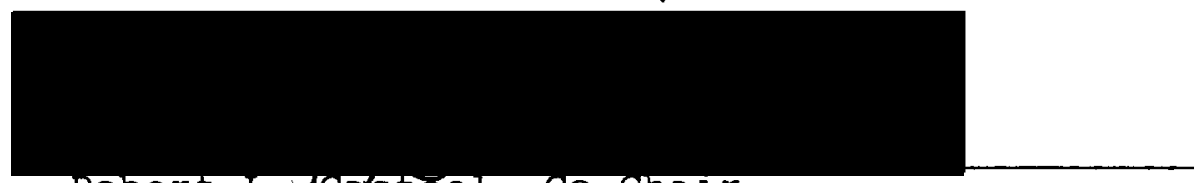

Robert L. Jca'stèel, co-chair

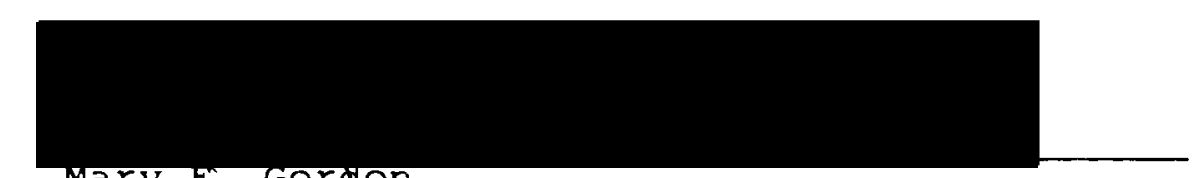

Mary E. Gorgon

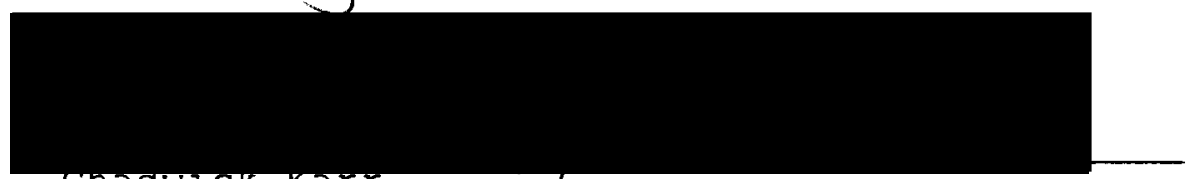

ChadWIek Karr

\section{APPROVED :}

Ineodore G. Grove, Heaa, Department or speech Communication 


\section{ACKNOWLEDGEMENTS}

There are many people to whom I owe a special note of appreciation for their help. I could not have done this project without them.

To Dr. Lee Ann Golper, my committee co-chair and advisor, my sincerest thanks for her help; she directed and edited patiently and reassured me when I needed it most. To Dr. Robert Casteel, my co-chair, my appreciation for his enthusiastic support and guidance throughout the project. I wish to thank Dr. Gregory Smith for his help and advice regarding statistical analyses and research design. I am most appreciative of the helpful criticisms and suggestions offered by Dr. Chadwick Karr and Mary Gordon in preparing the final draft. I am deeply indebted to the staff of the Speech Pathology Department of the Veteran's Administration Medical Center, Drs. Robert Marshall and Marie Rau, for their support, encouragement and patience over the past year. To Donna Graville my sincerest appreciation for not only helping with the reliability data but also for always being there to encourage me.

To those wonderful gentlemen, who so kindly agreed to give their time and energy to be subjects for this study, I extend my sincerest thanks. 
Lastly, I wish to thank my husband, Ron, for his encouragement, sound advice and understanding. Without his belief in me this project would not have been possible. 
TABLE OF CONTENTS

PAGE

ACKNOWLEDGEMENTS

i i i

LIST OF TABLES •. • . . . . . . . . . . . . . vii

LIST OF FIGURES . . . . . . . . . . . . . . . viii

CHAPTER

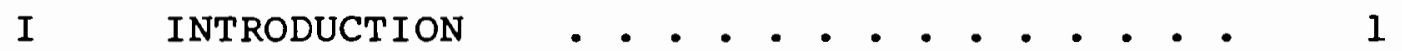

Purpose ............ 2

Definitions ......... . 2

II REVIEW OF THE LITERATURE

Introduction .......... . 4

Literature Review ....... . 4

III METHODS . . . . . . . . . . 22

Subjects . . . . . . . . . 22

Design . . . . . . . . . . . 23

IV RESULTS AND DISCUSSION . . . . . . . 31

Results ............ 31

Discussion ..... . . . 37

V SUMMARY AND IMPLICATIONS . . . . . . . 42

Summary . . . . . . . . . 42

Clinical Implications . . . . . . 43

Implications for Further Research . . 44 
PAGE

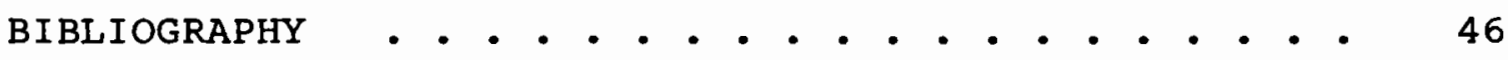
APPENDIX 


\section{LIST OF TABLES}

TABLE

PAGE

I Inter-rater Reliability: Percent of

Agreement Among Three Judges . . . . . . 30

I Raw Scores and Means for Non-Brain

Damaged Group . . . . . . . . . . . 32

I I Raw Scores and Means for Aphasic Group . . . . 33

IV Raw Scores and Means for Right Hemisphere

Damaged Group . • . . . . . . . . . 34

$\mathrm{V}$ Analyses of Variance (ANOVA) on Group $\mathrm{x}$

Frequency of Six Variables . . . . . . 35

VI Analyses of Variance (ANOVA) on Group $\mathrm{x}$

Duration of Six Behavior Variables . . . 36

VII Tukey Test for Intergroup Differences on

Groups and Smile Frequency . . . . . . 


\section{LIST OF FIGURES}

FIGURE

PAGE

1. Illustration of Positioning During the

Interview: Top view . . . . . . . 25

2. Illustration of Positioning During the

Interview: Side View . . . . . . 26 


\section{CHAPTER I}

\section{INTRODUCTION}

The study of nonverbal behavior after cortical damage has been extensive, but mainly limited to subjects with aphasia. Several researchers have examined the gestural abilities of aphasic patients (Cicone, Wapner, Foldi, Zurif \& Gardner, 1979; Duffy \& Duffy, 1981; Peterson \& Kirshner, 1981; Feyereisen \& Seron, 1982; Daniloff, Noll, Fristoe \& Lloyd, 1982; and Behrmann \& Penn, 1985). The focus of this work has been a determination of whether or not patients with aphasia, a language disorder, suffer from a corresponding disorder of their gestural abilities. Interest in the nonverbal behavior of patients with right hemisphere damage (RHD) has been motivated by the observation that communication does not proceed normally after RHD despite the intact verbal ability of these patients (Hier, Mondlock \& Caplan, 1983; Burns, Halpner \& Mogil, 1985; Golper, 1985; Kirshner, 1986; Meyers, 1986; Gorelick \& Ross, 1987). Several studies have noted that this group of patients particularly seems to display limited facial expressiveness (Buck \& Duffy, 1980; and Benowitz, Bear, Rosenthal, Mesulam, Zaidel \& Sperry, 1983). Other 
forms of nonverbal movements accompanying speech have not been examined among RHD subjects.

The present study compared the frequency and duration differences in coverbal behaviors displayed by aphasic subjects, RHD subjects and nonbrain damaged (NBD) subjects when engaged in conversation. This study replicates methods from an earlier investigation which focused solely on aphasic speakers (Katz, Market \& LaPointe, 1979).

\section{PURPOSE}

The purpose of this study was to examine for between group differences comparing aphasic subjects, RHD subjects and nonbrain damaged subjects with limited regard to six coverbal behaviors. The six behaviors were eye contact, head nod, head shake, head tilt, smile, and eyebrow raise.

It was hypothesized that the aphasic groups scores would not differ significantly (at $p$.01) from normals, while the RHD group would differ from normals and the aphasic group across each variable examined.

\section{DEFINITIONS}

Aphasia. A deficit in the ability to formulate, retrieve or decode the arbitrary symbols that make up language (Holland, 1977).

Coverbal. Gestures of the face, head and hands that accompany speech but do not stand on their own as meaningful (Markel, 1975). 
Discourse. Conversation; also the art or manner of conversing (Webster, 1943).

Dyadic interactions. Communicative interaction in which there are two participants.

Linguistic. Of or pertaining to language or the study of language (Webster, 1943).

Nonverbal. All of those human responses that are not overtly manifested in spoken or written words (Knapp, 1972 ). 


\section{CHAPTER II}

\section{REVIEW OF THE LITERATURE}

\section{INTRODUCTION}

This literature review is divided into five sections: the first section examines coverbal behavior in human communication; the second section discusses the deficits associated with aphasia; the third section examines the behavioral and cognitive changes subsequent to right hemisphere damage (RHD); the fourth section examines coverbal behavior in aphasic patients; and the final section examines coverbal behavior after RHD.

\section{LITERATURE REVIEW}

Coverbal Behavior in Communication

Researchers in human communication have for many years underscored the importance of coverbal gestural behavior when speaking and listening. Any nonverbal behavior that accompanies speech was labeled as "kinesics" by Birdwhistell (1970). Birdwhistell observed that inappropriate nonverbal behavior makes it difficult to communicate successfully. As he stated, "We can bear inappropriate behavior only if we can anticipate the inappropriate behavior" (Birdwhistell, 1970). 
Markel (1975) originated the term coverbal behavior, defining it as the gestures of the face, head and hands that accompany speech but do not stand on their own as meaningful. Markel examined the following coverbal gestures: head nods, head shakes, head tilts, eye contact, eyebrow raises, and smiles. Markel noted that these gestures tend to be conversational regulators in dyadic interactions.

Davis (1986) described gestural behaviors in dyadic conversation as important to the initiation and maintenance of topics, the recognition of who is the speaker and the regulation and management of conversational turns. He divided conversational gestures into two types:

housekeeping (turn-taking, listener interest, maintenance of conversational roles) and substantive (Iinguistic conversational repairs).

Other authors have examined the role of coverbal behaviors. Hadar, Steiner, and Rose (1985) extensively studied the head movements of people involved in dyadic conversation. They concluded that during listening, head movements signal interest, attention, agreement, a desire for a speaking turn and impatience. On the expressive side of an interaction, head movements studied by Hadar, Steiner, Grant, and Rose (1984) were found to begin just before the initiation of speech both at the beginning of speaking turns 
and at syntactic boundaries. They concluded that these head movements play a role in the regulation of conversational turns as well as marking meaning and emphasis in speech. These authors theorize that head movements may aid a speaker in the initiation of the complex motor movements needed for speech, leading them to propose utilizing these movements in the treatment of aphasic patients.

One can readily see the importance of coverbal

behavior to successful interactions. They are essential to managing and maintaining conversational interactions. Discourse without these movements becomes ambiguous and disjointed.

Language Deficits Associated with Aphasia

Aphasia has been described as a deficit in the ability to formulate, retrieve or decode the arbitrary symbols that make up language (Holland \& Reinmuth, 1982). This broad description includes not only oral speech and language but graphic, and presumably, gestural language as well.

The most commonly applied model of aphasic language dysfunction is that described by wernicke in 1880. Love and Webb (1986) gave an account of the basic ideas of Wernicke's theories in which various areas of the left cerebral hemisphere are said to be associated with different language functions. Damage to specific areas will cause a characteristic deficit in some aspect of language 
functioning. Nonfluent aphasias, characterized by sparse or telegraphic verbal output with rather good auditory comprehension, are usually associated with injuries to the left frontal cortex. The "speech areas" near the inferior left frontal motor strip areas are associated with motor programing for verbal output. Fluent aphasias are characterized by good oral motor ability and relatively impaired auditory comprehension. The damage that causes a fluent aphasia is usually posterior in the left temporoparietal areas of the brain. This is the area primarily responsible for the sensory reception and decoding of speech and language.

Brookshire (1986), as well as Goodglass and Kaplan (1972), add two types of "transcortical" aphasia to Wernicke's classical syndromes. The transcortical aphasias are said to be the result of lesions which isolate the language areas from the rest of the cortex. Transcortical aphasias are marked by the intact ability of the patient to repeat what was said. Transcortical motor aphasia is markea by sparse verbal output. Transcortical sensory aphasia causes the patient to have fluent, empty speech.

Currently, aphasiologists tend to divide aphasia into two basic types: fluent and nonfluent, with subtypes under some of these (Brookshire, 1986). There are three types which are considered fluent aphasias. Wernicke's aphasia is 
characterized by poor auditory comprehension, fluent but empty speech, good prosody, often correct grammar and often paraphasic speech. Conduction aphasia is said to be the result of a "disconnection" by a lesion to the arcuate fasiculus which is the associate pathway between the motor speech area and the comprehension area. Patients with this type of aphasia primarily have difficulty with repetition. oral reading is also impaired. Sometimes considered a mild version of Wernicke's aphasia, anomic aphasia causes primarily word retrieval difficulties. Patients with this type of aphasia have mild comprehension problems and tend to talk around the specific words they are unable to retrieve. Nonfluent aphasia is usually described as synonymous with Broca's aphasia. Although the motoric problems are the most prominent features of Broca's aphasia, linguistic (language) problems may be present as well. According to Brookshire (1986), these patients tend to lose the ability to generate grammatical sentences, maintaining the use of content rich telegraphic utterances instead.

This has been a brief outline of the basic language deficits associated with aphasia. The deficits of the aphasic person are quite different from those of the RHD patient. 
Cognitive Changes Associated with

Right Hemisphere Damage

Unlike persons suffering left hemisphere damage, right hemisphere damage rarely leads to aphasia. These patients, however, are known to have cognitive problems which may have an indirect effect on communication.

Hier and co-workers (1983) identified 12 deficits associated with right hemisphere damage after stroke. In their study they examined 41 patients with lesions in the right hemisphere following unilateral stroke. The most common cognitive deficits identified in these patients were, in descending order of occurrence: constructional apraxia, unilateral spatial neglect in drawing, dressing apraxia, left neglect, prosopagnosia, and anosagnosia. Ninety-three percent of the patients studied demonstrated constructional apraxia; the inability to copy block designs. The authors noted that 85 percent of the patients neglected the detail on the left side of the designs copied and drew more detajls on the right side. Fifty-one percent of their subjects demonstrated dressing apraxia, the inability to orient clothing when dressing. Forty-six percent of the subjects tested were judged to have left neglect, an inattention to the left side of the patient's environment. Prosopagnosia is the inability to recognize familiar faces; in this study 44 percent of the subjects could not identify pictures of Presidents Carter and Reagan or Senator Edward Kennedy. The 
least frequently noted deficit in this patient population was anosagnosia. Only 36 percent of the patients in the study demonstrated a denial of illness (anosagnosia).

Burns and her associates (1985) separate RHD cognitive deficits into five categories of clinical syndromes. Left neglect, anosagosia, and prosopagnosia fall into the category of visuoperceptual disorders. Visuomotor disturbances are defined as dressing disturbances and constructional apraxia. Burns also identifies affective and emotional alterations (discussed in the portion devoted to coverbal behavior after RHD) as a syndrome associated with RHD. The fourth and fifth categories are memory disorders and neuropsychiatric disorders. Memory disorders associated with RHD involve recall of visual material; after RHD some patients have difficulty remembering complex visual material and faces. Another form of memory disorder after RHD involves confusion over spatial orientation; patients will insist that an unfamiliar environment is, in fact, one they know very well. Neuropsychiatric disturbances following RHD can take the form of mania, visual hallucinations, and paranoia as well as acute confusional states.

Wapner, Hamby and Gardner (1981) noted that after RHD, patients have difficulty understanding complex linguistic material. The authors attribute this deficit to the inability to utilize context in written material to gain 
meaning. The authors found RHD subjects unable to appreciate humor, figures of speech or affectively-toned material. These subjects had a tendency to focus on insignificant details, personalize stories or fail to comprehend the moral of a story. When the authors presented the subjects with incongruities in the text the subjects tended to deal with them by confabulating in order to fit the detail into the story rather than challenging the veracity of the text. Burns et al. (1985) attribute this inability to comprehend abstract language, metaphor, humor, proverbs, idiomatic language or emotional language as a tendency of the intact left hemisphere to interpret in a word-by-word fashion. Literal or concrete interpretation of abstract language will result if it is analyzed sequentially; an appreciation of the utterance as a whole and the context in which it occurs is needed to understand complex language.

A more broadly based deficit may underscore and connect these deficits. In the larger Hier and co-workers' (1983) study, a factor analysis was performed on the deficits they found in their 41 subjects. Three factors emerged. Factor I was paresis (the paralyses of the contralateral side), factor II was the visuospatial aspect and factor III was "inattention." This inattention factor was described as the inability to direct and sustain 
attention. It was hypothesized that this deficit forms the basis for the denial of illness, the inability to recognize faces and constructional apraxia. Burns et al. (1985) wrote that this inattention may be an imperception rather than denial. These authors further explained that this may also be at the core of the observation that RHD patients tend to be impaired in the ability to express emotion. They postulate that there may be an imperception of emotion. Meyers (1986) observed that the right hemisphere may be quite different in structure and anatomical correlates than the left hemisphere. Whereas abilities have been specifically linked to discrete areas of the left hemisphere, this is not necessarily the case with the right hemisphere. She has suggested that cognitive schema of the right hemisphere may operate quite differently from the left in that it is more diffusely organized. Burns and her associates (1985) note that the right hemisphere is responsible for synthetic reasoning and the left for analytic reasoning. The nature of right hemisphere abilities makes them more elusive to testing and pinpointing. Meyers does point out, however, that research in this area is relatively new compared to the elaborate localization studies that have been done with the left hemisphere and, comparatively, that much less is known about the right hemisphere. 
Coverbal Behavior and Aphasia

Holland observed (1977) that many aphasic patients should not be able to communicate as much or as well as they actually do given the extent of their language impairments. She stated that, "Usually suprasegmental, gestural and contextual cues are quite heavily relied on by the aphasics I have observed." Communication can proceed in spite of limited language. According to Holland, communicative competence relies on more than intact language skills. In general, pragmatic skills are preserved in aphasia as the person continues to be able to convey communicative intent and obey the rules of discourse in a given context.

Collins (1983) wrote that patients with global aphasia retain an understanding of the supralinguistic parameters of speech such as emotional tone, body language and gestures. These patients are able to express surprise, anger, remorse and sorrow despite their global aphasia. Collins proposes that some nonverbal skills may be diversely represented in the cortex and therefore more resistant than linguistic skills to disruption by a focal lesion. These nonverbal skills may not require verbal mediation.

Daniloff et al. (1982) found that aphasic patients were able to recognize iconic gestural systems (Amerind) leading to the authors to conclude that the aphasia exhibited in their subjects was a disorder specific to the 
linguistic system rather than a general representational disorder.

Behrman and Penn (1985) conducted a study of gestural abilities in a group of aphasic subjects. Their findings indicated that the nonverbal, gestural abilities which accompany speech may be retained in the face of linguistic deficits. Skill in the area of gesture accompanying verbal communication correlated poorly with standardized measures of aphasia in their study. Rather, type of aphasia was correlated with gestural ability. Subjects with nonfluent aphasias were more skilled at using gestures that aided communication and supported or substituted for their verbal output. Fluent subjects in this study tended to have vague, unintelligible gestures. Their gestures were judged to interfere with communication more often than those of the nonfluent subjects.

Peterson and Kirshner (1981) reviewed several studies of gestural ability in aphasic patients. They cited two points of view with regard to gestural ability in aphasic persons. Some researchers believe that deficits in gestural ability in this population are due to a central deficit in representational ability. Alternatively, several authors have suggested the deficit lies in the motoric aspect of aphasia; that is, the gestural deficits are a component of apraxia (Peterson \& Kirshner, 1981). Peterson and Kirshner 
concluded that gestural output may mirror speech output. The person with a nonfluent aphasia may use sparse, simple, singular, appropriate gestures whereas the person with a fluent aphasia may use clustered and unclear gestures. Glosser, wiener and Kaplan (1986) found that the gestural rate of their aphasic subjects (as a function of time and as function of spoken words) did not differ from normal controls. Further, they found that nonfluent aphasic persons produced more gestures per word than either fluent subjects or normal subjects.

Schienberg and Holland (1980) analyzed a ten-minute sample of conversation between two fluent aphasic patients with severe auditory comprehension deficits. They noted that the two subjects retained the ability to follow the rules of discourse in dyadic conversation. The patients maintained turn-taking in spite of their deficits in selfmonitoring. Some of the turn-taking markers noted as appropriate included the use of coverbal behaviors in the conversation (e.g., head nodding to indicate agreement while the other person is speaking). Although the linguistic, or propositional, content of the conversation was inadequate, the two aphasic speakers managed to retain an appropriate conversational interaction. This point suggests that communicative competence may be present in spite of 
linguistic deficit, and that this communicative competence may be attributed to factors other than verbal skill.

Katz et al. (1979) investigated the coverbal behaviors of aphasic speakers and correlated them with language abilities. This study served as a model for the methods and areas examined in the present study. In the Katz et al. study, subjects were asked to comment on twenty topics while they were videotaped. The subjects were allowed to talk as long as they liked about each topic introduced by the examiner. The subjects were ten aphasic patients with Porch Index of Communicative Ability (PICA) (Porch, 1967) scores below the $85 \mathrm{th}$ percentile overall, at least three months post onset and with diagnoses of aphasia. Controls were matched for age and education. The videotapes were viewed and scored by two judges. Reliability measures indicated good agreement between the two judges. Occurrences and durations of six behaviors were tracked: eye contact, eyebrow raise, head tilt, head nod, head shake, and smile. Three behaviors were found to differ from normals. Duration of eye contact, head shake and head nod were longer for aphasic speakers than for normals. Eye contact duration correlated inversely with verbal performance on the PICA. They found that the lower the subjects' verbal subtest scores were, the longer the mean length of eye contact. The authors concluded that aphasic speakers seemed to be better 
communicators than language users as their coverbal

behaviors appear to be unaffected by their linguistic deficits.

Davis (1986) stated that even the most severely impaired patient with Wernicke's type of aphasia can use "housekeeping" types of gestures. He defined those as the gestures that speakers use to indicate turn-taking and interest on the part of the listener and for maintaining conversational roles.

In the preceding section, several studies were reviewed and a general picture emerges to suggest that most aphasic speakers retain certain pragmatic skills that allow them to be more able communicators than their verbal skills would indicate. Some of this ability may be attributable to nonverbal and coverbal skills.

Coverbal Behavior after Right Hemisphere Damage

Meyers (1984) stated that the patient with right hemisphere damage (RHD) may be deficient, in a generalized way, to appreciating experience itself. An impairment in perception and the ability to grasp the essence of a given situation may result in a feeling of unconnectedness with the world that manifests itself in pragmatic difficulties. Communication deficits will become most apparent when the person is engaged in conversation. Meyers noted that these 
patients demonstrate a "reduced sensitivity to the communicative situation and the pragmatic aspects of communication" (p. 75).

Burns and her co-workers (1985) have written an extensive treatment and assessment protocol for the RHD population. In their work, they outlined the communicative problems that can be associated with right hemisphere strokes. The primary communication deficit, according to these authors, is impaired pragmatic communication, both in the realm of the proposition (conveying information in context) and in the performative (use of nonverbal as well as verbal aspects of communication to convey messages). The RHD person tends to disregard the conventions of discourse. Information rendered may violate the presuppositions of the two speakers. The information may be overly detailed, tangential and personal. In general, the speaker with RHD shows disregard for the listener's interest, knowledge and experience. The RHD patient demonstrates deficits in his nonverbal communication: lack of eye contact; facial expression; and failure to use the "regulators" of conversational turn-taking. Burns defined regulators as shifts in eye contact and head movements which indicate the listener's interest level and signal turn-taking or topicshifting. These are coverbal aspects of communication. 
Several studies to date have implied that right hemisphere disease is associated with reduced facial affect. Buck and Duffy (1980) showed that judges consistently rated RHD patients as nearly as inexpressive in their facial expression as subjects with Parkinson's disease and much less expressive than aphasic subjects. Kirshner (1986) stated that RHD patients tend to be unemotional or apathetic, unself-conscious, and generally have a flat affect as opposed to left hemisphere damaged (LHD) patients. Emotional content will often aid the comprehension ability of the patient with LHD whereas the RHD patient may entirely miss the emotional aspect of a message but readily perceive the literal content of the message.

In a study by Gorelick and Ross (1987), 14 RHD subjects were studied. The purpose of the study was to determine the ability of these patients to interpret and express affective states through prosody and facial gesture. Twelve of these subjects were judged to be impaired in the ability to either imitate or create an emotional expression through prosody and facial expression or to interpret the affective state of the examiner. The examiners used the same linguistic material with differing intonation and facial expression to assess these patients, eliminating the possibility of grasping meaning from the propositional content alone. To assess expressive ability, the 
researchers asked the subjects to alter their expressive prosody and facial expression to either match the examiner's or to express a prescribed emotion. All but two of the subjects were impaired in some or all of these aspects. The authors concluded that damage to the right hemisphere often impairs a person's ability to express and/or interpret meanings of oral language through facial expression or intonation.

Ross and Mesulam (1979) presented two cases of patients unable to express emotion after right hemisphere strokes. They described the patients as having expressionless faces and monotonous voice qualities. They speculated that the right hemisphere might have a dominant role in the modulation of the affective components of speech.

Benowitz and associates (1983) studied the comparative abilities of aphasic patients, RHD patients and normals to evaluate the meaning of a person's facial expressions. They found the RHD subjects unable to interpret films of a person expressing several emotions without benefit of accompanying audio tape. Aphasic patients and normal controls were unimpaired in this ability. They found the RHD subjects to have deficits in the perception of facial expression, in the interpretation of intonational qualities of the voice and in the appreciation of emotional stories and humor. The 
authors concluded that the right hemisphere is critical in evaluating the significance of social interactions through nonverbal cues and particularly through facial expressions. The literature suggests that a person sustaining damage to the left hemisphere may suffer from impaired language, but not necessarily impaired communication. Conversely the patient with RHD may not demonstrate language disturbance, but he may suffer from communicative impairment as a result of pragmatic deficits. Coverbal behaviors form an important component of pragmatic ability; they are essential to effective discourse. 


\section{CHAPTER I I}

\section{METHODS}

\section{SUBJECTS}

Two experimental groups and one normal control group of ten subjects each were drawn from a population of brain injured and normal speakers at the Portland Veteran's Administration Medical Center (PVAMC). All three groups were comprised of men, aged 45-70 years. The two experimental groups contained subjects who: 1) had unilateral, thrombo-embolic cerebrovascular accidents; 2) were at least three months post onset at the time of videotaping; and 3) had computerized axial tomography (CT) scans and/or neurological examinations and histories indicating a unilateral infarction. All subjects were native English speakers.

The aphasic subjects in this study had a "functional" level of communicative ability based on their PICA Overall percentile scores. The overall scores for these subjects fell between the $53 \mathrm{rd}$ and the 94 th percentile. All subjects were premorbidly right handed with the exception of one left handed, left hemisphere-injured subject included in the 
aphasic group, as he apparently had a left hemispheric dominance for language.

All subjects in the right hemisphere damaged (RHD) group were screened for any subtle evidence of aphasia and were found to have no language deficits. All of the RHD subjects were right-handed males. Both experimental groups had equivalent distributions with regard to anterior versus posterior sites of lesion. (See Appendix for detailed descriptions of the three groups.)

The non-brain damaged (NBD) group included subjects selected to match the brain damaged subjects across age, education level, race and occupation level. The NBD subjects were drawn from patients, volunteers and employees of the PVAMC.

\section{DESIGN}

All subjects were interviewed prior to the videotaping and asked to identify three events or circumstances to discuss during the videotaping. They were asked to be prepared to discuss a time in their lives when they were very happy, an event or circumstance when they were very sad and something that makes them very angry. All subjects were advised as to the nature of the study and signed video taping release documents. The subjects were asked to converse for a minute and a half on each preselected topic. 
Subjects were prompted when to begin. Every sample required some degree of interaction from the interviewer to keep the subject talking about his chosen topic for the full time. The samples were conversational rather than monologues. The camera was located just above the interviewer's right shoulder. The subjects' heads and upper chests were in view. (See Figures 1 and 2 for diagrams of the interview configuration.)

Each videotaped segment was edited to be exactly 90 seconds long. The taped segments were then randomized across both topics and subjects. The experimental samples contained the video-only portion of the recording with a total of 90 randomized segments. In addition, ten samples were presented twice as a means to later examine intra-rater reliability. To establish inter-rater reliability, two judges viewed ten of the samples and their scores were compared with those of the primary investigator.

The video tapes were reviewed at least six times to count and time the occurrences and durations of eye contacts, eyebrow raises. Eye contact was defined as when the subject looked the interviewer in the eye, i.e., each time the subject looked away and re-established eye contact, the judge tallied an event of eye contact. The clock was stopped each time the subject looked away and restarted when the subject returned to the eye contact position. Head nod 
25

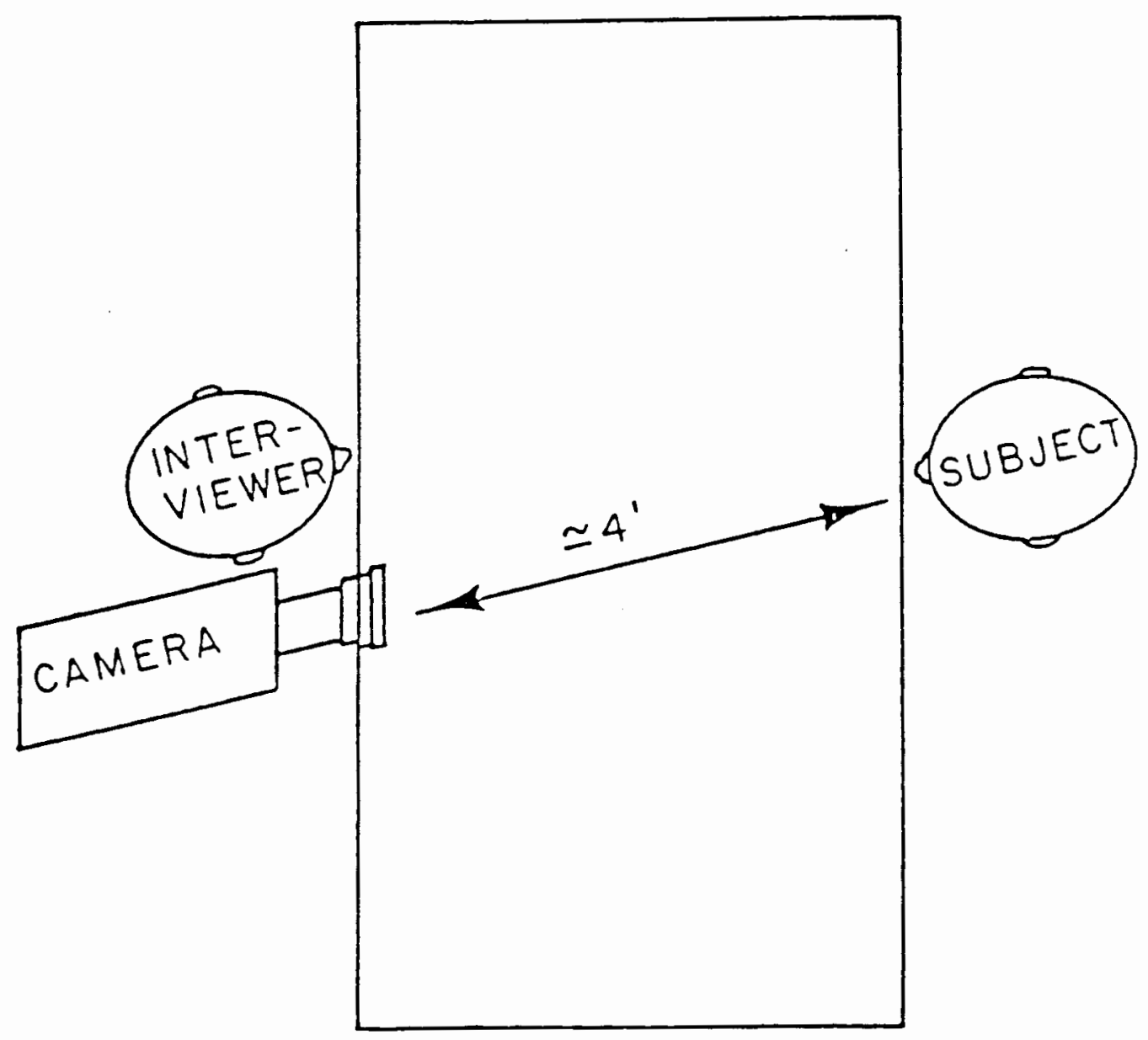

Figure 1. Illustration of Positioning During the Interview: Top View. 


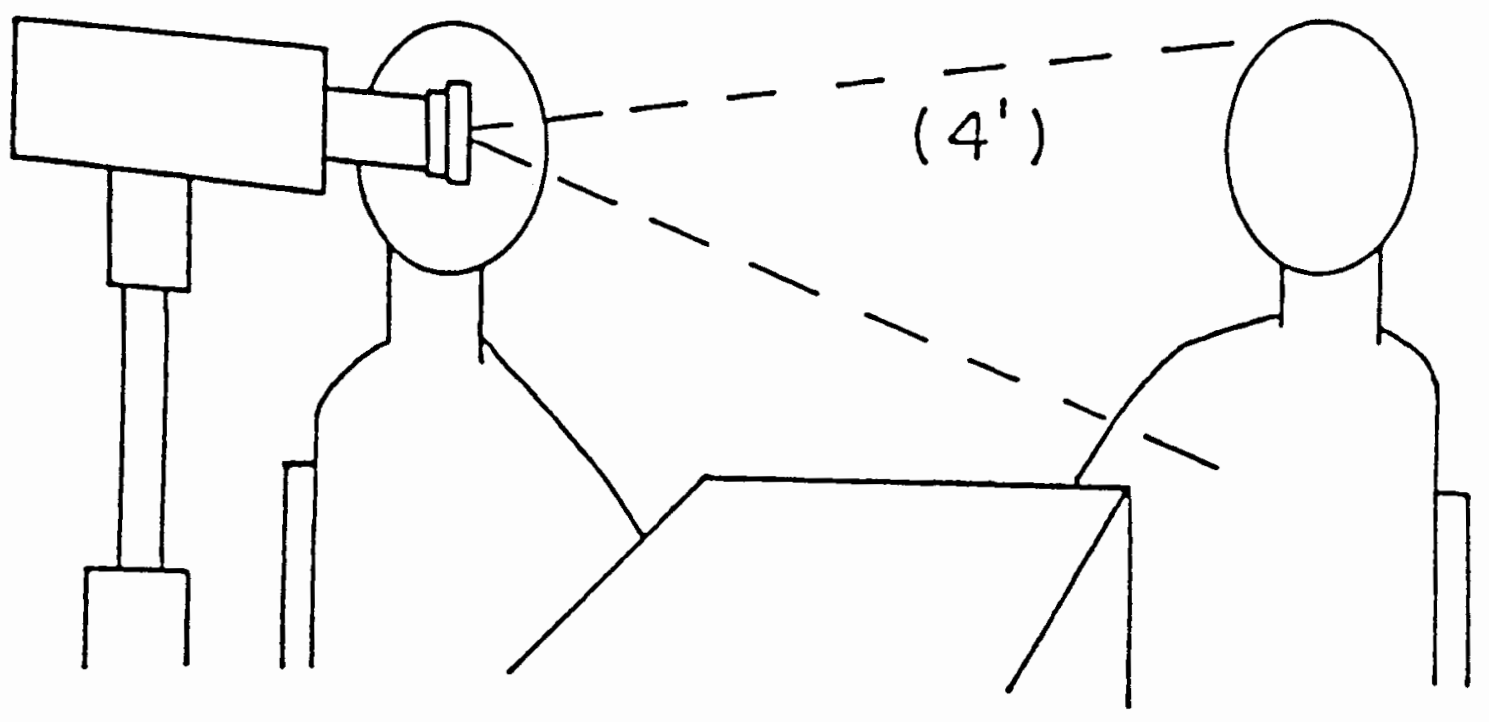

Figure 2. Illustration of Positioning During the Interview: Side View. 
was defined as the vertical movement of the head. Head shake was defined as the horizontal, side-to-side movement of the head. Head nods and shakes were counted as single events from the start of the movement to the cessation of movement rather than counting individual nods or shakes. Head tilts were defined as angled movements of the head from the neck up, not to include inadvertent head tilts resulting from posture shifting. Smiles were defined as the upward turning of the corners of the mouth. Eyebrow raises were defined as the upward motion of the eyebrows. A training tape was prepared to allow the judges to practice scoring prior to the actual data collection. This training tape was comprised of subjects who were not included in the study. Judges were shown some examples of the six behaviors but not taken step-by-step through an entire sample. Judges were able to count and time the events simultaneously with a push button lap counter (used in sports activities) and a stop watch with "time-in, time-out" capability. The lap counter was held in the left hand and the stop watch in the right. The judge would press both the counter and the stop watch simultaneously when a particular behavior occurred and stop the clock when the behavior ended. The stop watch, a Cronus, kept accumulated time so that at the end of a tape segment the total time could be recorded. This method of scoring allowed the judge to count and time without looking 
away from the screen. The primary experimenter was unaware of group membership during the scoring as no identifying information was contained in the recorded samples.

\section{Data Analysis}

The frequency and duration scores for each segment were sorted according to subject number; the scores from the subjects' three different segments were totaled across the three samples for the data analysis. After frequency and duration scores were computed the data were sorted by group. Means were computed for each group's performance across each of the twelve variable (six frequency variables and six duration variables). One way analyses of variance (ANOVA) were applied to group $\mathrm{x}$ frequency and group $\mathrm{x}$ duration comparisons in each of the six behaviors for a total of twelve analyses. An $F$ statistic was applied to identify significant differences at $p<.01$. The Tukey test was applied as well to each ANOVA to examine for between group differences. Intra-rater and inter-rater reliabilities were examined with percentage of agreement computations.

Reliability

Inter-rater reliability was established on a percentage of agreement basis. Two judges' scores were compared with those of the primary investigator on ten samples. Frequency measures had to be plus or minus two to 
be considered an agreement. Total duration counts had to be within five seconds on eye contact and three seconds on all other measures to be considered in agreement. The agreement percentages for each variable were averaged across the ten samples for an overall agreement percentage in each variable (see Table I). Judges more consistently agreed on frequency measures; the range of percentages being from 83 percent agreement on head tilt frequency to 100 percent on smile frequency. Agreement on duration measures ranged from 56 percent to 100 percent, with head tilt again having the lowest rate of duration agreement.

Intra-rater reliability was established by comparing the scores of ten repeated samples recorded by the primary experimenter. The same system of percentage of agreement was used. Agreement was 100 percent for all variables with the exception of eye contact frequency (90\%) and head tilt duration (90\%). 
TABLE I

INTER-RATER RELIABILITY: PERCENT

OF AGREEMENT AMONG THREE JUDGES

VARIABLE

FREQUENCY

DURATION

Eye Contact

908

$73 \%$

Head Nod

$93 \%$

$90 \%$

Head Shake

$76 ㅇ$

$100 \%$

Head Tilt

$83 ㅇ$

$56 \%$

Smile

1008

93

Eyebrow Raise

$96 \%$

$86 ㅇ ㅜ ㅇ$ 


\section{CHAPTER IV}

\section{RESULTS AND DISCUSSION}

\section{RESULTS}

Following the completion of frequency and duration measures by the primary investigator and judges scoring for reliability comparisons, all raw scores for each subject number were summed and sorted according to group membership. Mean values were then computed across each variable (Tables I-III). Although the data from Tables II, III and IV show the RHD group's means to be lower on nearly all of the coverbal behaviors measured, the majority of these differences were not found to be statistically significant.

of the 12 variables examined with ANOVAs, only one yielded a significant difference between the groups (Tables $\mathrm{V}$ and $\mathrm{VI})$. The analysis of group $\mathrm{x}$ frequency of smile was significant at the $p<.01$ level (Table V). The Tukey Test for between group differences revealed the source of variation to be a difference between the RHD group and the NBD group at the $\mathrm{p}<.01$ level (Table VII). The RHD subjects smiled less frequently than both the NBD group and the aphasic group. The comparisons of the aphasic group with the NBD group showed no significant differences. 


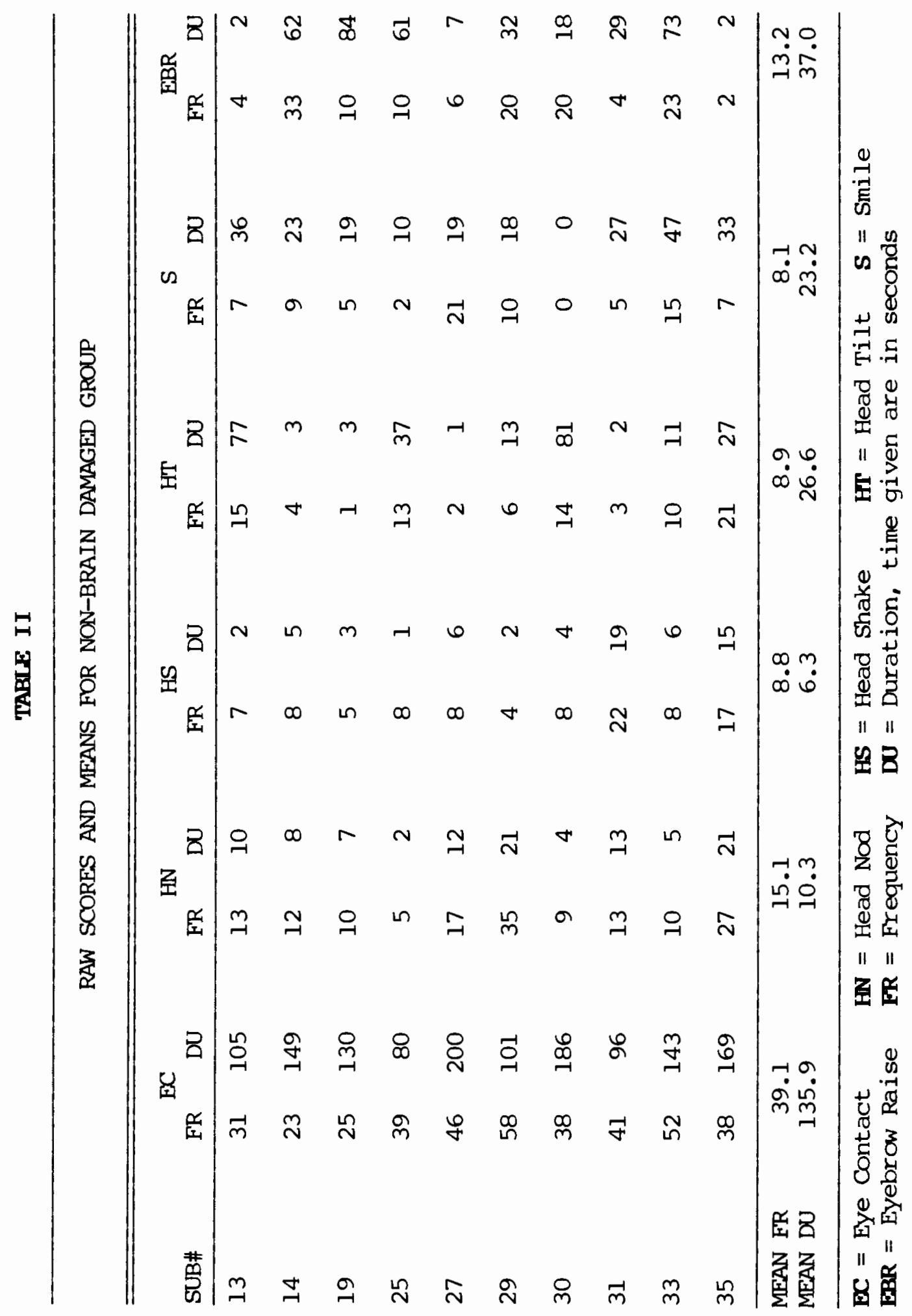




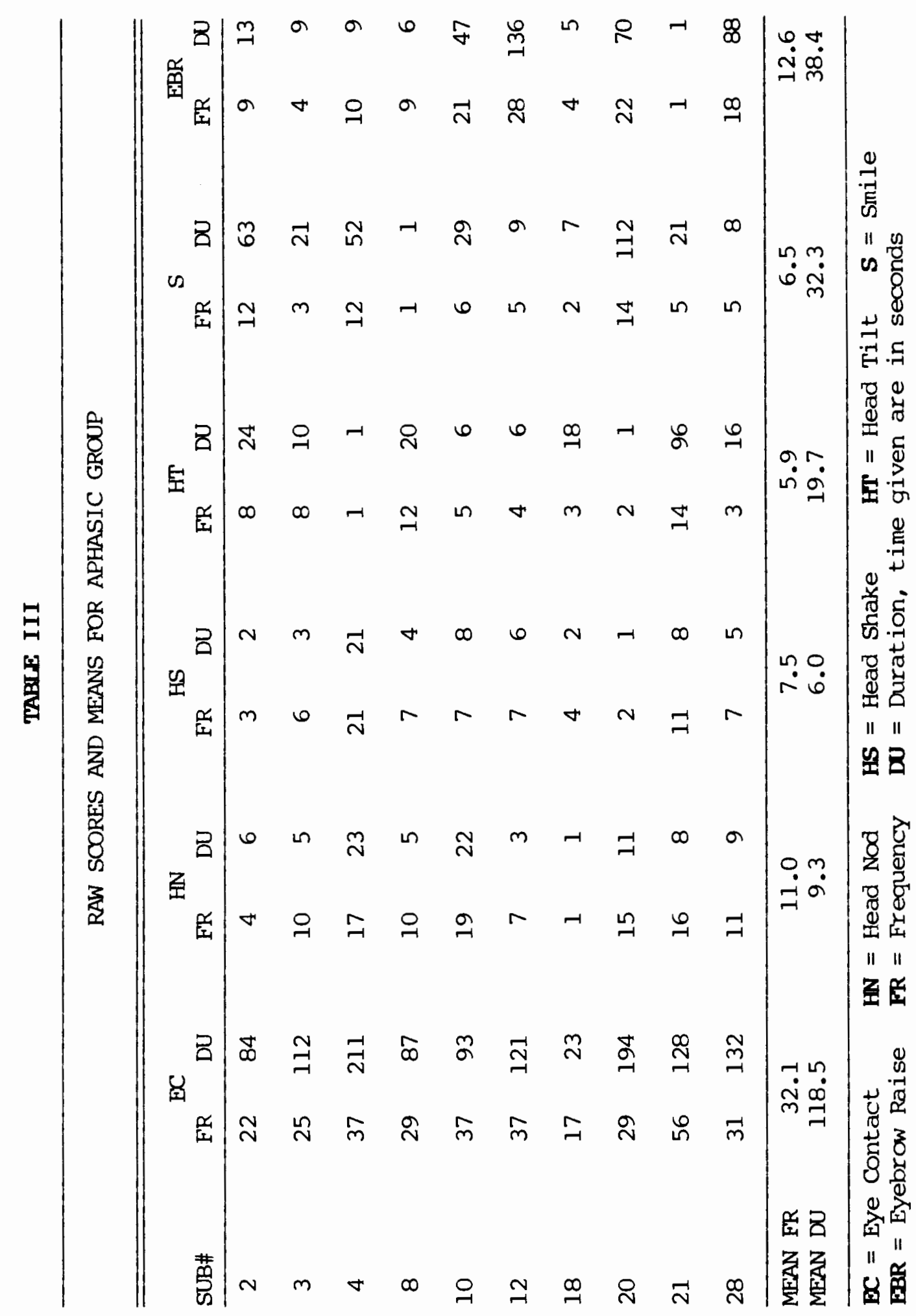




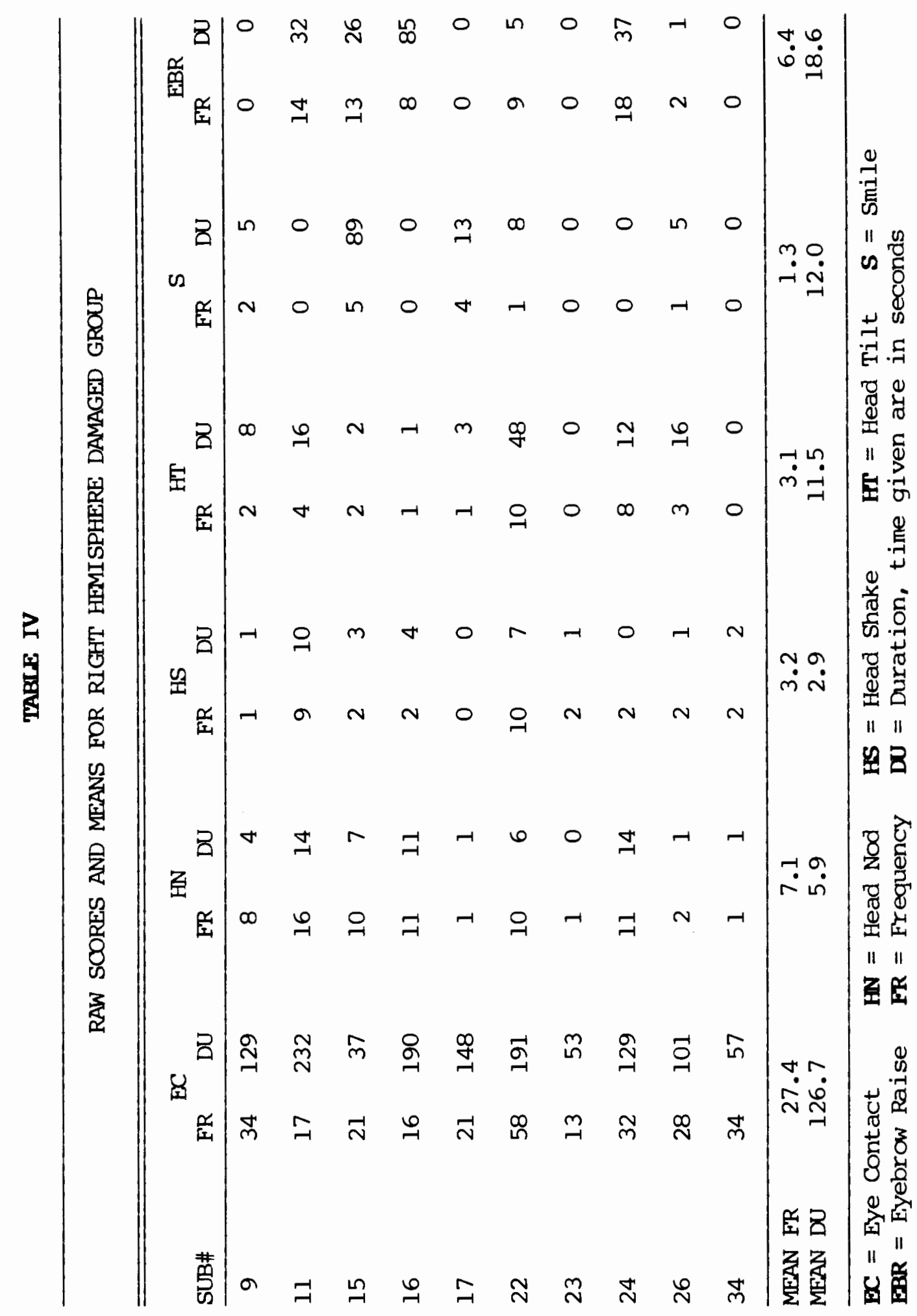




\section{TABLE V}

\section{ANALYSES OF VARIANCE (ANOVA) ON GROUPS $X$ FREQUENCY OF SIX \\ BEHAVIOR VARIABLES}

\begin{tabular}{lrrrrr}
\hline SOURCE & $\begin{array}{c}\text { SUMS OF } \\
\text { SQUARE }\end{array}$ & $\begin{array}{c}\text { DEGREES OF } \\
\text { FREEDOM }\end{array}$ & $\begin{array}{c}\text { MEAN } \\
\text { SQUARE }\end{array}$ & $F$ & P VALUE \\
\hline Eye Contact & 694.867 & 2 & 347.433 & 2.54 & .10 \\
& 3717.300 & 27 & 137.678 & & \\
Head Nod & 320.067 & 2 & 160.033 & 3.26 & .05 \\
& 1323.800 & 27 & 49.030 & & \\
Head Shake & 171.800 & 2 & 85.900 & 3.26 & .05 \\
& 709.700 & 27 & 26.285 & & \\
Head Tilt & 168.267 & 2 & 84.133 & 3.29 & .05 \\
& 688.700 & 27 & 25.507 & & \\
Smile & 252.800 & 2 & 126.400 & 6.10 & .01 \\
& 559.500 & 27 & 812.300 & & \\
Eyebrow Raise & 283.467 & 2 & 141.733 & 1.81 & .18 \\
& 2116.400 & 27 & 78.385 & & \\
& & & & & \\
\hline
\end{tabular}




\section{TABLE VI}

\section{ANALYSES OF VARIANCE (ANOVA) ON \\ GROUPS $X$ DURATION OF SIX \\ BEHAVIOR VARIABLES}

\begin{tabular}{lrrrrr}
\hline SOURCE & $\begin{array}{c}\text { SUMS OF } \\
\text { SQUARE }\end{array}$ & $\begin{array}{c}\text { DEGREES OF } \\
\text { FREEDOM }\end{array}$ & $\begin{array}{c}\text { MEAN } \\
\text { SQUARE }\end{array}$ & $F$ & P VALUE \\
\hline Eye Contact & 408.800 & 2 & 204.400 & .07 & 1.00 \\
& 79061.500 & 27 & 2928.204 & & \\
Head Nod & 106.400 & 2 & 53.200 & 1.22 & .30 \\
& 1171.100 & 27 & 43.374 & & \\
Head Shake & 70.867 & 2 & 35.433 & 1.33 & .28 \\
& 721.000 & 27 & 26.704 & & \\
Head Tilt & 1142.867 & 2 & 571.433 & .903 & 1.00 \\
& 17089.000 & 27 & 632.926 & & \\
Smile & 2067.800 & 2 & 1033.900 & 1.46 & 2.50 \\
& 19081.700 & 27 & 706.730 & & \\
Eyebrow Raise & 2441.867 & 2 & 1220.933 & .96 & 1.00 \\
& 34362.800 & 27 & 1272.696 & & \\
\hline
\end{tabular}




\title{
TABLE VII
}

\section{TUKEY TEST FOR INTERGROUP DIFFERENCES}

ON GROUPS AND SMILE FREQUENCY

\author{
For Group 1 (NBD) vs. Group 2 (Aphasic): \\ $Q=1.111$ \\ For Group 1 (NBD) vs. Group 3 (RHD) : \\ $Q=4.724$ \\ For Group 2 (Aphasic) vs. Group 3 (RHD): \\ $Q=3.612$ \\ Degrees of Freedom: 27

$$
\begin{aligned}
& \mathrm{p} \text { at } .01=4.450 \\
& \mathrm{p} \text { at } .05=3.490
\end{aligned}
$$

Three frequency measures (head nod, head shake, and head tilt) approached a level of significant difference between the groups (Table IV) with probability values at, but not less than, .05 . None of the duration scores differed between groups (see Table V).

\section{DISCUSSION}

The results of this study are interpreted to indicate that the initial hypothesis that the RHD subjects would demonstrate significantly different scores in frequency and duration of coverbal behaviors than normals and aphasic subjects is rejected. Although on several measures the mean scores of the RHD subjects were lower than either the 
aphasic group or the NBD group, there was a great deal of variation within each group and thus the differences were not significant.

The one variable that was found to be significant was the relatively reduced frequency of smiles in the RHD compared to normals and aphasic subjects. The mean frequency of smiles for the NBD group was 8.11; for the aphasic group it was 6.5 , but for the RHD group it was only 1.3. Half of the subjects in this group did not smile at any time during the four and a half minutes of video taped conversation. Averaging the scores of just those RHD subjects who did smile resulted in a mean score of only 2.6 . Among all of the coverbal behaviors studied, the smile variable was the only affective variable studied. All the other behaviors could be neutral with regard to conveying emotion. This leads to speculation that perhaps the communicative deficits of the RHD patient are more broadly based in a deficit of emotional expression rather than strictly a deficit in coverbal behavior. This theory would be supported by the research of Ross and Mesulam (1979), Buck and Duffy (1980), Hier et al. (1983), Benowitz et al. (1983), and Gorelick and Ross (1987). These studies have all suggested the RHD patients have deficits in the ability to express emotion as well as in interpreting the emotional expression of others. The present study found that RHD 
subjects were not remarkably less animated in any behavior studied except for the one conveying a specific emotion.

The smile variable was also the most reliably measured variable of the six behaviors. Judges agreed 100 percent of the time on the frequency and 93 percent of the time on the duration of smiles.

The other experimental group in this study, the aphasic group, did not differ from the NBD on frequency or duration of any variable. The raw scores of the aphasic group were very close to those of the NBD group on all behaviors. This supports the Katz et al. study (1979) finding of no significant differences, with regard to coverbal behavior, between aphasic and normal speakers. By abstraction, this might also account for some of the turntaking ability demonstrated by the two aphasic subjects in Schienburg and Holland's study (1980). The study only briefly mentioned head nodding as an encouragement for the other party to continued talking, since coverbal behavior was not the intended focus of their study. But perhaps the intact coverbal behaviors of the aphasic subjects contributed to their conversational turn-taking abilities. According to Davis (1986), the very coverbal behaviors examined in the present study are those essential to the regulation of turns in a dyadic conversation. The findings of the present study support the observations by Schienburg 
and Holland (1980) that aphasia does not interfere with other (nonlanguage) aspects of discourse behavior. The NBD group showed a great deal of variability with regard to frequency and duration of coverbal behaviors. Smiling frequencies, for example, ranged from 0-21. Eyebrow raises ranged in frequency from 2-33. There are no normative studies available with which to compare these subjects; one would speculate from these data that people in the course of conversation tolerate a wide range of frequencies and durations of coverbal behavior without suspecting an affective deficiency. All of the normal subjects (as well as the aphasic subjects) made many facial and head movements of one kind or another during the taped conversations. Some individual RHD subjects, however, made almost no movements of any kind during the samples. Subject number 23, for example, made only 13 eye contact moves, one head nod and one head shake during the entire four-and-ahalf minute sample; he did not smile or raise his eyebrows at any time. It is doubtful that anyone would view this subject's coverbal style as normal.

This study demonstrated that a group of RHD subjects had reduced (with differences approaching significance) frequencies of movement in conversational interactions when compared to subjects matched for age, sex, and education with no brain injury and subjects with aphasia. These 
differences were not remarkable with the exception of the frequencies of smiles. Larger groups of subjects might help to determine if these differences were notable trends. The differences in frequency of smiles are consistent with previous studies suggesting RHD persons have reduced emotional facial gestures. 


\section{CHAPTER V}

\section{SUMMARY AND IMPLICATIONS}

\section{SUMMARY}

The purpose of this study was to compare variations in coverbal behaviors among aphasic subjects, right hemisphere damaged (RHD) subjects, and nonbrain damaged (NBD) subjects. Ten aphasic subjects, ten RHD subjects and ten NBD subjects were videotaped while in conversation. The frequency and duration of six head and facial movements were tallied including: eye contact, head nods, head shakes, head tilts, smiles and eyebrow raises. Analyses of variance were applied to the individual totals across variables and between group differences were tested. The ANOVAs resulted in only one statistically significant difference at the .01 level. The RHD group was found to smile significantly less than both the aphasic group and the normal control groups $(p<.01)$. The frequency mean scores for three other nonverbal behaviors were low in the RHD group in comparison to the two groups, but the difference variation did not quite reach statistical significance. The aphasic group's scores were not statistically different from those of the normal group. 


\section{CLINICAL IMPLICATIONS}

The relatively intact coverbal abilities of aphasic subjects, as demonstrated in this study, may be viewed as encouragement for clinicians to utilize more pragmatic methods of aphasia treatment. The speech clinician, the family members, as well as the patient himself/herself tend to focus on the patient's linguistic deficits and discount the coverbal communicative ability the patient retains. Of course the linguistic deficits of these patients need attention, but a greater emphasis on general communication might make treatment more effective.

Another implication for clinicians might be in the counseling of patients and their families concerning the affective changes after RHD. Patients should be encouraged to be aware of their decreased affect and how it might effect those around them. Families should be discouraged from making assumptions about the internal emotional state of the patient without verbally confirming their beliefs. The RHD patient enjoys the advantage of intact linguistic ability; however, as wapner et al. (1981) suggested, these patients tend not to appreciate subtleties. In the process of normal language development, children learn at a young age that it is inappropriate to comment directly on someone's behavior, but that it is sometimes acceptable to do so indirectly or subtly. Some patients with RHD lose 
this distinction, between direct and indirect language. In counseling patients and their families, the clinician might explain these changes to them and emphasize the need for directness when discussing their affective behavior.

\section{IMPLICATIONS FOR FURTHER RESEARCH}

This study objectively assessed components of facial expressions and head movements in certain coverbal behaviors. By collecting data on a limited range of behaviors thought to be usually exhibited, the hope was to find a difference in some of these behaviors to account for the subjective observation that patients with language impairment are able to communicate effectively while RHD patients with intact language often experience disruption in effective communication. This was a quantitative rather than a qualitative analysis. The more common method of assessing facial expression is to have judges make subjective assessments of a subject's expressiveness. The intention of this study was to quantify head and neck movements. Throughout the data collection phase of the experiment, it was the feeling of the primary experimenter, as well as the judges, that the critical elements that differentiated the groups might be more subjective. Perhaps the differences lie in the fact that there are a wide range of movements possible to express not only emotion but also 
affiliation with the conversational partner. Perhaps subjective listener assessments are more closely analogous to perceptions of disorders in coverbal behaviors. There should be research comparing subjective analyses with frequency analyses.

Another area for research is an investigation of the internal emotional states of the RHD patient population relative to their affect. Does the outward expression differ from the subjective feeling of the patient? A limitation of the present study was the small sample size, only ten subjects in each of the groups. A larger sample could assess how coverbal behavioral changes interact with its relationship to other cognitive problems, the location of cortical damage, severity of aphasia or type of aphasia. This study examined occurrences and durations of certain coverbal behaviors. To place these behaviors in the context of communication, a follow-up investigation could explore the content of the verbal statements that corresponded to each coverbal movement. Is there dysynchrony or movement occurring at inappropriate junctures or lacking when they ought to occur? These issues await further study. 


\section{BIBLIOGRAPHY}

Behrmann, M. and C. Penn (1985). Nonverbal communication of aphasic patients. The British Journal of Disorders of Communication, 19, 239-251.

Benowitz, L.I., D.M. Bear, R. Rosenthal, M.M. Mesulam, E. Zaidel, and R.W. Sperry (1983). Hemispheric specialization in nonverbal communication. Cortex 14. l. 5-11.

Birdwhistell, R.L. (1970). Kinesics and context. Philadelphia: University of Pennsylvania Press.

Buck, R. and R.J. Duffy (1980). Nonverbal communication of affect in brain damaged patients. Cortex 16, 351-362.

Burns, M.S., A.S. Halper, and S.I. Mogil (1985). The clinical management of right hemisphere dysfunction. Aspen Systems Corporation, Rockville, Maryland.

Brookshire, R.H. (1986). Aphasia. Minneapolis: BRK Publishers.

Cicone, M., W. Wapner, N. Foldi, E. Zurif, and H. Gardner (1979). The relation between gesture and language in aphasic communication. Brain and Language, $\underline{8}, 324-$ 349 .

Collins, M.J. (1983) Global aphasia: Knowledge in search of understanding. Communicative Disorders, 8, 125136.

Daniloff, J.K., J.D. Noll, M. Fristoe, and L.L. Lloyd (1982). Gesture recognition in patients with aphasia. Journal of Speech and Hearing Disorders, 47, 43-49.

Davis, G.A. (1986). Pragmatics and treatment. In R. Chapey Language Intervention Strategies in Adult Aphasia. Baltimore: Williams and Wilkins.

Feyereisen, P. and X. Seron (1982). Nonverbal communication and aphasia: A review. Brain and Language, 16, 191212 . 
Glosser, G., M. Wiener, and E. Kaplan (1986). Communicative gestures in aphasia. Brain and Language, 27, 345-359.

Golper, L.A.C. (1985). Nonverbal communication after hemispheric disease. In Darby (Ed.) Speech and language evaluation in neurology: Adult disorders. New York: Grune \& Stretton.

Golper, L.A.C., M.E. Gordon, and M.T. Rau (1983). Coverbal behavior and perceptions of organicity. In Brookshire (Ed.) Clinical aphasiology; 1983 conference precedings. Minneapolis: BRK Publishers.

Gorelick, P.B. and E.D. Ross (1987). The aprosodias: Further functional-anatomical evidence for the organization of affective language in the right hemisphere. Journal of Neurology, Neurosurgery, and Psychiatry, 50, 553-560.

Hader, U., T.J. Steiner, and F.C. Rose (1985). Head movements during listening turns in conversations. Journal of Nonverbal Behavior, $9,35-43$.

Hadar, U., T.J. Steiner, and F.C. Rose (1984). The timing of shifts of head postures during conversation. Elsevier Science Publishers B.V. (North-Holland).

Hier, D.B., J. Mondlock, and L.R. Caplan (1983). Behavioral abnormalities after right hemisphere stroke. Neurology, 33, 337-344.

Holland, A.L. (1977). Some practical considerations in aphasia rehabilitation. In M. Sullivan and M.S. Kommers (Eds.) Rationale for adult aphasia therapy, Omaha, NB: University of Nebraska Medical Center.

Holland, A.L. and O.M. Reinmuth (1982). Aphasia in adults. In G.H. Shames and E.H. Wiig (Eds.) Human communication disorders: An introduction. Columbus: Charles E. Merrill Publishing Co.

Katz, R.C., L.L. LaPoint and N.N. Markel (1979). Coverbal behavior and aphasic speakers. In Brookshire (Ed.) Clinical aphasiology; 1979 conference proceedings. Minneapolis: BRK Publishers.

Knapp, M.L. (1972). Nonverbal communication in human interaction. New York: Holt, Rinehart and Winston. 
Kirshner, H.S. (1986). Behavioral neurology: A practical approach. New York: Churchill Livingstone.

Goodglass, H. and E. Kaplan (1972). The assessment of aphasia and related disorders. Philadelphia: Lea \& Febiger.

Love, R.J. and W.G. Webb (1986). Neurology for the speechlanguage pathologist. Boston: Butterworths.

Markel, N.N. (1975). Coverbal behavior associated with conversational turns. In Kendon, Harrison and Key (Eds.), Theory of behavior in face-to-face interaction. The Hague: Mouton.

Myers, P.S. (1986). Right hemisphere communication impairment. In $R$. Chapey Language intervention strategies in adult aphasia. Baltimore: Williams and Wilkins.

Meyers, P.S. (1984). Right hemisphere impairment. In A. Holland (Ed.) Language disorders in adults. San Diego: College Hill press.

Peterson, L.N. and H.S. Kirshner (1981). Gestural impairment and gestural ability in aphasia: A review. Brain and Language, $14,333-348$.

Porch, B.E. (1967). The Porch index of communicative ability. Palo Alto: Consulting Psychologists Press.

Ross, E.D. and M.M. Mesulam (1979). Dominant Language functions of the right hemisphere? Prosody and emotional gesturing. Archives of Neurology, 36, 144148 .

Schienberg, S. and A.L. Holland (1980). Conversational turn taking in Wenicke's aphasia. In Brookshire (Ed.) Clinical aphasiology: Conference proceedings, 1980. Minneapolis: BRK Publishers.

Wapner, W., S. Hamby and H. Gardner (1981). The role of the right hemisphere in the apprehension of complex linguistic materials. Brain and Language, 14, 15-33. 


\section{APPENDIX}

SUBJECT PROFILES

RACE, HANDEDNESS AND PREVIOUS OCCUPATIONS

OF APHASIC SUBJECTS

\begin{tabular}{|c|c|c|c|}
\hline Subject \# & Race & Handedness & Previous Occupation \\
\hline 002 & C & Left & Speech Pathologist \\
\hline 003 & C & Right & Career Coast Guard \\
\hline 004 & C & Right & Salesman \\
\hline 008 & $\mathrm{C}$ & Right & Owned/Managed Business \\
\hline 010 & C & Right & Teacher \\
\hline 012 & C & Right & Salesman \\
\hline 018 & C & Right & Sawmill Worker \\
\hline 020 & $B$ & Right & Maintenance Engineer \\
\hline 021 & C & Right & Postal Clerk \\
\hline 028 & $\mathrm{C}$ & Right & Cab Driver \\
\hline
\end{tabular}


AGE AND MONTHS POST ONSET

OF APHASIC SUBJECTS

\begin{tabular}{|c|c|c|}
\hline Subject \# & Age & Months Post Onset \\
\hline 002 & 62 & 5 \\
\hline 003 & 53 & 51 \\
\hline 004 & 59 & 17 \\
\hline 008 & 63 & 11 \\
\hline 010 & 70 & 14 \\
\hline 012 & 62 & 36 \\
\hline 018 & 67 & 38 \\
\hline 020 & 50 & 12 \\
\hline 021 & 62 & 5 \\
\hline \multirow[t]{2}{*}{028} & 58 & 3 \\
\hline & $\begin{aligned} \text { Mean } & =60.6 \\
\text { Range } & =50-70\end{aligned}$ & $\begin{array}{l}19.2 \\
3-51\end{array}$ \\
\hline
\end{tabular}


LOCATION OF INFARCTION, TYPE OF APHASIA,

PICA OVERALL PERCENTILES, AND YEARS

OF EDUCATION OF APHASIC SUBJECTS

\begin{tabular}{|c|c|c|c|c|}
\hline Subject \# & $\begin{array}{l}\text { Location of } \\
\text { Infarction }\end{array}$ & $\begin{array}{l}\text { Type of } \\
\text { Aphasia }\end{array}$ & $\begin{array}{l}\text { PICA O.A. } \\
\text { Percentiles }\end{array}$ & $\begin{array}{l}\text { Years of } \\
\text { Education }\end{array}$ \\
\hline 002 & Posterior & Fluent & 86 & 18 \\
\hline 003 & Ant./Post. & Nonfluent * & 63 & 12 \\
\hline 004 & Posterior & Fluent & 83 & 13 \\
\hline 008 & Posterior & Fluent & 94 & 12 \\
\hline 010 & Anterior & Nonfluent* & 77 & 16 \\
\hline 012 & Anterior & Nonfluent* & 78 & 13 \\
\hline 018 & Posterior & Fluent & 75 & 11 \\
\hline 020 & Anterior & Nonfluent* & 73 & 12 \\
\hline 021 & Ant./Post. & Fluent* & 67 & 13 \\
\hline \multirow[t]{2}{*}{028} & Anterior & Nonfluent* & 88 & 16 \\
\hline & & $\begin{array}{l}\text { Mean } \\
\text { Range }\end{array}$ & $\begin{array}{l}=78.4 \\
=63-94\end{array}$ & $\begin{array}{l}13.6 \\
11-18\end{array}$ \\
\hline
\end{tabular}

*Subjects with facial asymmetry 


$$
\begin{aligned}
& \text { RACE, HANDEDNESS AND PREVIOUS OR CURRENT } \\
& \text { OCCUPATIONS OF NORMAL SUBJECTS }
\end{aligned}
$$

\begin{tabular}{|c|c|c|c|}
\hline Subject \# & Race & Handedness & occupation \\
\hline 013 & $\mathrm{~B}$ & Left & Career Army \\
\hline 014 & C & Right & Army Chaplain \\
\hline 019 & C & Right & House Painter \\
\hline 025 & C & Right & Career Navy \\
\hline 027 & C. & Right & Salesman \\
\hline 029 & C & Right & High School Counselor \\
\hline 030 & C & Right & Construction worker \\
\hline 031 & C & Right & Teacher \\
\hline 033 & C & Left & Real Estate Broker \\
\hline 035 & C & Right & Researcher \\
\hline
\end{tabular}




\section{AGES AND YEARS OF EDUCATION \\ OF NORMAL SUBJECTS}

\begin{tabular}{|c|c|c|c|}
\hline Subject \# & Age & Years & of Education \\
\hline 013 & 49 & & 14 \\
\hline 014 & 74 & & 19 \\
\hline 019 & 72 & & 8 \\
\hline 025 & 57 & & 16 \\
\hline 027 & 51 & & 12 \\
\hline 029 & 59 & & 18 \\
\hline 030 & 60 & & 9 \\
\hline 031 & 62 & & 16 \\
\hline 033 & 66 & & 12 \\
\hline \multirow[t]{2}{*}{035} & 49 & & 18 \\
\hline & $\begin{aligned} \text { Mean } & =59.9 \\
\text { Range } & =49-74\end{aligned}$ & & $\begin{array}{l}14.2 \\
8-18\end{array}$ \\
\hline
\end{tabular}


RACE, HANDEDNESS AND PREVIOUS OCCUPATIONS OF RIGHT HEMISPHERE DAMAGED SUBJECTS

\begin{tabular}{llll}
\hline Subject \# & Race & Handedness & \multicolumn{1}{c}{ Occupation } \\
\hline 009 & C & Right & Construction Worker \\
011 & C & Right & Salesman \\
015 & C & Right & Commercial Fisherman \\
016 & C & Right & Accountant \\
017 & C & Right & General Contractor \\
022 & C & Right & Career Navy \\
023 & C & Right & Salesman \\
024 & C & Right & Motel Manager \\
026 & C & Right & Social Worker \\
034 & C & Right & Career Coast Guard \\
\hline
\end{tabular}


AGE AND MONTHS POST ONSET OF RIGHT

HEMISPHERE DAMAGED SUBJECTS

\begin{tabular}{|c|c|c|}
\hline Subject \# & Age & Months Post Onset \\
\hline 009 & 57 & 3 \\
\hline 011 & 63 & 60 \\
\hline 015 & 64 & 6 \\
\hline 016 & 67 & 3 \\
\hline 017 & 56 & 42 \\
\hline 022 & 45 & 3 \\
\hline 023 & 39 & 3 \\
\hline 024 & 58 & 3 \\
\hline 026 & 58 & 36 \\
\hline \multirow[t]{2}{*}{034} & 67 & 48 \\
\hline & $\begin{aligned} \text { Mean } & =57.4 \\
\text { Range } & =39-67\end{aligned}$ & $\begin{array}{l}20.7 \\
3-60\end{array}$ \\
\hline
\end{tabular}


LOCATION OF INFARCTION AND YEARS OF EDUCATION FOR RIGHT HEMISPHERE DAMAGED GROUP

\begin{tabular}{|c|c|c|}
\hline Subject \# & $\begin{array}{l}\text { Location of } \\
\text { Infarction }\end{array}$ & $\begin{array}{l}\text { Years of } \\
\text { Education }\end{array}$ \\
\hline 009 & Posterior & 12 \\
\hline 011 & Anterior* & 13 \\
\hline 015 & Anterior* & 12 \\
\hline 016 & Ant./Post. * & 14 \\
\hline 017 & Posterior & 12 \\
\hline 022 & Ant./Post.* & 12 \\
\hline 023 & Posterior & 12 \\
\hline 024 & Anterior* & 13 \\
\hline 026 & Ant./Post. & 18 \\
\hline \multirow[t]{2}{*}{034} & Anterior & 14 \\
\hline & & $\begin{array}{l}=13 \cdot 4 \\
=12-18\end{array}$ \\
\hline
\end{tabular}

*Subjects with facial asymmetry 